\title{
ANÁLISE DA IMPORTÂNCIA DA COMUNICAÇÃO ONLINE PARA O PÚBLICO INTERNO NA DIVULGAÇÃO DOS RESULTADOS OBTIDOS PELO IAPE
}

\author{
Nathalie Sarah Jaime ${ }^{1}$
}

\begin{abstract}
Resumo
O presente artigo tem como objetivo propor melhorias na comunicação institucional do Instituto de Atendimento e Pesquisa em Equoterapia (IAPE), localizado em Curitiba-PR. Para este trabalho, foi realizada uma pesquisa baseada na aplicação de questionários em um grupo de 50 pessoas. Como resultados, foram esperadas a melhora da comunicação e do diálogo entre o IAPE e seu público, a criação de um canal de comunicação de melhor e mais eficaz divulgação da prática da equoterapia. Com isso, espera-se maior abrangência no público atingido e reconhecimento das atividades desenvolvidas pelo IAPE entre seus próprio funcionários.

Palavras-chave: Planejamento em comunicação, comunicação online, equoterapia.
\end{abstract}

\begin{abstract}
The main purpose of this article is to suggest some measures to improve the institutional communication action of the Instituto de Atendimento e Pesquisa em Equoterapia (IAPE), located in Curitiba, State of Paraná, Brazil. To do this research, we asked 50 persons to answer a questionnaire. Among the results, we expect the improvement of the dialogue and communication between the IAPE and its public, the creation of a new communication channel in order to achieve a better dissemination of the practice of equotherapy. Thus, we expect that the activities developed by the IAPE have a better appreciation among its public and its employees.
\end{abstract}

Keywords: Communication planning, online communication, equotherapy.

\section{Introdução}

A equoterapia é um método terapêutico que faz uso do cavalo para reabilitar pessoas com deficiência. Mesmo que o seu surgimento tenha ocorrido há 15 anos no Brasil, essa técnica ainda é pouco conhecida, podendo ser considerada como um novo ramo a ser trabalhado no jornalismo de revista, diário, digital ou outras mídias. A equoterapia pode também ser nomeada de equitação terapêutica. Seus benefícios já são reconhecidos há muito tempo, como demonstra Copeland-Fitzpatrick \& Tebay (LEITÃO, 2004, p. 1):

A partir de 1960, a Equitação Terapêutica ganhou uma força crescente, resultante do reconhecimento já histórico das qualidades terapêuticas que o cavalo tem para o corpo e mente humanas. O termo passou então a ser usado para descrever todos os possíveis usos terapêuticos do cavalo.

Medeiros e Dias (2002, p.34) relatam ainda uma melhora de qualidade de vida através da equoterapia: "Os benefícios psicossociais proporcionados pela Equoterapia, são adquiridos

\footnotetext{
${ }^{1}$ Jornalista, especialista em Comunicação Empresarial e Institucional pela Universidade Tecnológica Federal do Paraná (UTFPR).
} 
por motivação que impulsiona o indivíduo pelo desejo e prazer, conseguindo atrair a atenção e com isso aumentar o grau de concentração, de iniciativa, autoestima, autocontrole, autoconfiança, gerando liberdade e independência para maior interação social".

O Instituto de Atendimento e Pesquisa em Equoterapia (IAPE), fundado em janeiro de 2009, é uma entidade sem fins lucrativos que tem como finalidade o tratamento, a pesquisa e o desenvolvimento de projetos ligados à reabilitação pela equoterapia. Quando analisamos a questão empresarial do IAPE, podemos notar que atualmente o meio base da empresa adquirir novos investidores (empresas e pessoas colaboradoras no apadrinhamento e manutenção do centro) é através do seu público interno. O IAPE fica localizado nas dependências da Sociedade Hípica Paranaense, na cidade de Curitiba, e atende 50 pacientes. O local tem se tornando centro de referência e adquiriu visibilidade em grandes congressos nacionais e internacionais através das ações que vem desenvolvendo.

Diante deste cenário, este projeto tem como problema: poderá a comunicação online ajudar o público interno do Instituto de Atendimento e Pesquisa em Equoterapia na divulgação dos resultados obtidos por esta instituição? Para tanto, o objetivo geral consiste em desenvolver uma melhor comunicação institucional com os clientes e potenciais investidores do Instituto de Atendimento e Pesquisa em Equoterapia (IAPE) através da comunicação online. Os objetivos específicos são: conhecer o público-alvo da instituição, identificar quais os meios de comunicação que a instituição já possui com seus clientes, proporcionar um meio de comunicação online entre o IAPE e seus clientes, bem como mostrar que o jornalismo online tem a capacidade de destacar a qualidade de vida do indivíduo com deficiência de vida usando o recurso da equoterapia. Este trabalho se justifica pois a equoterapia é um tema importante a ser tratado, dada sua contribuição social. Muitos pais de crianças com deficiências ainda não conhecem a técnica que poderia ajudar numa melhora do quadro clínico de seus filhos, ajudando tanto em uma maior independência, como melhor convívio social.

\section{Briefing}

Atualmente na cidade de Curitiba são reconhecidos apenas três centros de prática de equoterapia. Sendo eles: Centro de Desenvolvimento e Pesquisa em Equoterapia Soldado Josué Cipriano Diniz, o Instituto de Atendimento e Pesquisa em Equoterapia e por fim, Pégasus Centro de Equoterapia. Este projeto contempla apenas um dos centros supracitados, o 
Instituto de Atendimento e Pesquisa em Equoterapia, ou IAPE, pois é atualmente o maior centro localizado na cidade de Curitiba.

O IAPE é o único na cidade de Curitiba a ter uma parceria com a rede pública (Hospital de Clínicas da Universidade Federal do Paraná), e dedica 25\% do total de atendimentos a pacientes carentes. Para que seja possível aumentar o atendimento de pacientes carentes, existe ainda a ação de apadrinhamento. Essa atividade é constituída de uma pessoa ou empresa doadora que custeie as despesas do paciente carente na equoterapia (podendo optar por 1 ou 2 aulas semanais).

O Instituto de Atendimento e Pesquisa em Equoterapia possui hoje poucos meios de comunicação com seu público, sendo esses canais constituídos apenas de painéis e folders. Os painéis, cartazes de $1 \mathrm{mX} 1 \mathrm{~m}$, são veiculados quando a instituição tem algum funcionário em congresso. Os folders, que ficam dispostos no balcão do IAPE para que os interessados em divulgar o centro possam levar para outras pessoas, possuem somente informações básicas de contato e como funciona o Instituto. Os folders possuem um único modelo, realizado pelas sócias, e trazem apenas um lado impresso de 1/4 de folha A4.

O IAPE possui 2 tipos de públicos: interno e externo à organização. O interno compreende os funcionários, pais de alunos, alunos, profissionais e contratados de serviços gerais. O público externo da organização compreende os futuros investidores e novos pais de pacientes. O presente estudo busca interagir, em um primeiro momento, com o público interno da organização.

O público interno considerado neste estudo se desmembra da seguinte maneira:

- 2 Fisioterapeutas.

- 1 Instrutor de Equitação.

- 3 Auxiliares.

- 50 pais de alunos.

- 50 alunos (diversas faixas etárias).

Um dos principais motivos da escolha por este público é o fato de que a maioria dos novos pacientes e investidores do instituto são adquiridos pelos próprios pais de pacientes dentro da empresa. Consolidar a imagem positiva da marca do IAPE é a forma de adquirir novos investidores e atuar nos públicos de interesse deste estudo. É através da comunicação para o público interno que será possível conseguir o investimento necessário para manter e dar mais condições de atender um número maior de pessoas no centro. 
O IAPE conta atualmente com duas empresas patrocinadoras: Eternit e Miara Krüger Tintas. Os investimentos feitos pelas empresas parceiras são doados em dinheiro para que possam ajudar pessoas bolsistas a saírem do programa de bolsa e contarem com este patrocínio, isto ajuda para que novas bolsas sejam concedidas para outras pessoas carentes.

O público interno é focado neste estudo para tornar influentes, informados e integrados todos os funcionários e pais de alunos da empresa. Os funcionários do IAPE estão empregados desde o seu início das atividades do instituto, cargos que possuem baixa rotatividade, devendo portanto dar voz ativa às pessoas que são parte da essência da empresa. Um dos objetivos, com isso, é possibilitar aos colaboradores do IAPE o conhecimento das transformações ocorridas no ambiente de trabalho de forma mais eficaz, via a comunicação online.

\section{Equoterapia}

A equoterapia é considerada um método terapêutico e educacional que faz uso do cavalo para reabilitar pessoas com deficiências. Comparado às técnicas de medicina tradicional, a equoterapia é considerada recente.

A Associação Nacional de Equoterapia (ANDE - BRASIL) é o órgão que regulamenta a atividade da equoterapia no Brasil. Uma de suas principais funções é a de "contribuir para a reabilitação e educação de pessoas com deficiência e/ou com necessidades especiais, mediante a prática da equoterapia”.

O trabalho equoterapêutico ainda está longe de atingir o conhecimento e divulgação que já se tem nos Estados Unidos e Europa. Percebe-se no site da North American Riding for the Handicapped Association, ou NAHRA, o avanço de poder encontrar um centro de equoterapia através da região onde a pessoa mora.

A equoterapia pode ser dividida em três principais áreas. Classificação que o IAPE (2009) retrata da seguinte forma:

- Hipoterapia: Indicada as pessoas portadoras de necessidades especiais, é um meio de reabilitação física e psíquica, utilizando os vários estímulos dados pelo cavalo em conjunto com técnicas específicas da fisioterapia e equitação.

- Equitação terapêutica: Indicada para pacientes que têm independência para se manter sobre o cavalo com o objetivo de estimular a organização espacial, sociabilização, linguagem e aprendizagem. 
- Pré-esportivo: O trabalho destina-se a crianças até seis anos aprendendo de forma lúdica as noções básicas da equitação desde o manejo, alimentação e hábitos do animal.

\section{Comunicação online}

A pesquisa bibliográfica permitiu verificar que, apesar de existirem vários trabalhos publicados que mencionam a equoterapia, a grande maioria destes são focados apenas na área médica. Esta razão foi uma das motivações que levou adiante esta pesquisa. Um dos grandes temas abordados ao longo deste trabalho é a comunicação online para empresas. A comunicação foi utilizada neste estudo, pois ela adquiriu uma grande importância no ambiente organizacional dos tempos modernos. Beserra de Faria (s.d, p.8) revela que:

A comunicação passou, nos últimos anos, a desempenhar um papel preponderante na vida das organizações. Tanto é verdade que vemos seu deslocamento de vias secundárias para o próprio staff das empresas, que passam a tê-la mais perto de si, prova da assunção de sua importância estratégica.

Busca-se com este estudo influenciar as sócias do IAPE a tomar a comunicação da empresa como algo preponderante, visto que a comunicação poderia abrir muito mais portas para a expansão do negócio. A comunicação online é essencial nos dias atuais, e não poderia deixar de ser para o instituto em questão, visto que as empresas têm que acompanhar o desenvolvimento da sociedade. Parte da responsabilidade por essa informatização foi motivada pelas próprias empresas. Manuel Castells (2006, p. 233 e 225) reafirma isto quando diz que:

se hoje a complexidade da tecnologia é imprescindível para as empresas, elas mesmas também foram motor, em certo sentido, da revolução digital. Além de ajudar a popularizar o microcomputador, a empresa em rede é a forma fundamental de concorrência na nova economia global.

Robert Srour (1998, p. 27) expõe a realidade de que "as organizações não mais ocupam lugares específicos e tendem a tornarem-se virtuais, porque é mais fácil e mais barato transportar a informação". No caso da empresa estudada, o IAPE, esta adaptação ao fácil e barato é essencial. Há alguns anos, meios de comunicação para empresas vêm buscando uma interatividade com os seus públicos, fazendo com que estes se tornem mais interessados com a mensagem a ser transmitida. As cartas aos leitores, os telefonemas de ouvintes e telespectadores, os talk-shows, a participação na construção de determinadas narrativas são 
alguns dos exemplos mais conhecidos de tais mecanismos. O mailing proposto para o IAPE busca neste mesmo viés a participação ativa de seu público, que ele seja feito para o público da instituição e por ele. Isso tomaria muito mais atrativo e interessante para o público envolvido, podendo a comunicação online trazer melhoras na qualidade do serviço prestado e estímulo para que o público apareça mais nesse meio de comunicação. SERRA (2006, p.7) relata este movimento quando expressa a seguinte ideia:

O (...) "jornalismo cívico" ou "jornalismo público" pode ser visto também, no seu conjunto, como uma tentativa de, a partir da interacção entre o jornalista e o público - uma interacção mediante a qual se tornará possível, ao primeiro, detectar as questões que verdadeiramente interessam o segundo -produzir uma informação comunitariamente relevante.

Além dessas vantagens competitivas da mídia online se busca cumplicidade com o público trabalhado, que ele possa expor suas opiniões e contribuir ativamente do processo de crescimento empresarial. Chaves de Melo (s.d, p.11) reforça essa ideia, quando diz que:

a Comunicação Interna na organização deve ser priorizada, os tabus devem ser derrubados, velhos paradigmas serão desprezados para a construção de um novo modelo de comunicação, onde todos os funcionários serão envolvidos e participantes. Procurando saber o que os funcionários pensam, serão a eles atribuídas responsabilidades pelo sucesso da implantação de estratégias que visem à melhoria dos negócios.

Ações comunicacionais em empresas devem buscar integração, para que reflitam expressivamente a imagem da organização para seus públicos. O IAPE hoje possui uma imagem institucional fraca $^{2}$, e por esta razão acaba não atraindo mais parceiros às suas propostas (inclusive de responsabilidade social - pacientes bolsistas). Estar fora do circuito da internet atualmente tira a possibilidade de qualquer empresa em expandir seus horizontes e conseguir se fixar no mercado, isso não difere para o Instituto de Atendimento e Pesquisa em Equoterapia.

\section{Metodologia}

Em um primeiro momento, foi realizada para este trabalho uma revisão bibliográfica sobre os temas constantes (equoterapia e comunicação online) contando com o suporte de

\footnotetext{
${ }^{2}$ Neste contexto, constitui-se uma imagem institucional fraca a falta de divulgação, de informação adequada, de reprodução do nome da instituição perante os públicos ao qual ela pretende se relacionar (seja ele interno, externo, ou mesmo apenas uma relação de troca de serviços).
} 
pesquisas em livros, revistas e internet. Após esta fase, foi feita a busca dos principais teóricos que ajudam a fundamentar os questionamentos propostos.

Em uma segunda etapa deste trabalho foi realizada uma pesquisa qualitativa com a elaboração de um questionário misto a ser aplicado no IAPE com os pais dos alunos da equoterapia. O tipo de pesquisa escolhida pelo trabalho para auxiliar na elaboração do informativo foi a qualitativa. Isto se deve a uma busca contínua de que o público-alvo participe ativamente do processo de produção da comunicação. A pesquisa qualitativa tem como característica a interpretação e preocupação do ambiente no qual se trabalha. "Enquanto o objeto deixa de ser tomado como um dado inerte e neutro, o sujeito é considerado como parte integrante do processo de conhecimento, atribuindo significados àquilo que pesquisa" (SANTAELLA, 2001, p.143).

Levando em consideração os 50 alunos do centro que realizam a equoterapia, a amostra se baseou nos depoimentos da totalidade dos pais dos pacientes. Justifica-se essa escolha visto que o universo a ser trabalhado é reduzido. O questionário foi constituído da seguinte maneira: 9 questões, sendo 8 questões fechadas e 1 questão aberta. Este questionário tem como finalidade descobrir o interesse do público alvo em receber um informativo, entregue de forma online, sobre o assunto da equoterapia.

Os dados dos questionários foram tabulados com relação à porcentagem de aceitação e avaliação dos principais pontos de interesse do público-alvo. O que se pretende analisar com este projeto é a viabilidade do mailing institucional como forma de divulgação da marca desta empresa.

\section{Análise dos resultados}

Nas primeiras 3 questões do questionário foi realizado um filtro, determinando assim a possibilidade de participação apenas do público interno compreendido no estudo. O filltro consistiu da seguinte forma:

- se a pessoa é pai de aluno/paciente: pois alguns deles são acompanhados apenas por empregados ou outros responsáveis, não caberia a eles essa comunicação proposta;

- se a pessoa possui e-mail: não adiantaria pesquisar a opinião de alguém que não se encaixa no perfil escolhido para se trabalhar em um primeiro momento;

- se a pessoa teria interesse em receber um informativo sobre equoterapia em seu email: esse último filtro foi aplicado para saber qual o número de interessados e focar 
as respostas do questionário em pessoas que tem o interesse e saibam como contribuir com o trabalho.

A participação dos membros, que passaram por este filtro, foi de $80 \%$, correspondendo assim a 40 entrevistados. Os outros $20 \%$ não passaram pelo menos em uma das perguntas de filtro da pesquisa. Independe nas perguntas de filtro se ele tem interesse no informativo, em um primeiro momento está se considerando restringir ao perfil de público pesquisado.

Quanto à periodicidade, foram dadas quatro opções, escolhidas após tomar como base outros informativos empresariais. A escolha, com $45 \%$ de aprovação do público-alvo, foi a circulação do informativo online $1 \mathrm{vez}$ ao mês.

Os conteúdos propostos para serem tratados nos informativos foram aceitos pelo público com grande porcentagem de votos, demonstrando assim que a pesquisa realizada segue o gosto do público interno da instituição. O público demonstrou interesse nos seguintes temas e o percentual de aprovação de:

1. Novidades sobre a prática de equoterapia $-92,5 \%$

2. História de alunos que tiveram êxito na sua recuperação $-75 \%$

3. Divulgação dos congressos em que o nome da Instituição está envolvido - 72,5\%

4. Catálogo de profissionais da área de saúde - 52,5\%

Uma das constatações realizadas com a pesquisa foi o grande interesse do público alvo em campanhas de sorteio de prêmios, obtendo $100 \%$ de interesse deste público. Esse interesse pode futuramente ser utilizado pelo IAPE para que sejam feitos brindes mensais com logo marca do instituto para este público.

A abordagem para que o informativo funcione como canal de melhorias para a qualidade do serviço obteve $82,5 \%$ da participação do público. Isso demonstra que os pais também possuem quesitos que achariam interessante colocar como melhorias e atualmente não possuem um canal de comunicação que melhore esta situação.

A pesquisa demonstrou um grande interesse por parte do público e pode futuramente funcionar de forma concreta na instituição, bastando apenas um esforço das pessoas responsáveis em dar continuidade ao trabalho, com base nos resultados.

\section{Considerações finais}

Após a realização de estudo de campo, foi possível perceber a necessidade e vontade do público pesquisado em fazer uso da comunicação online dentro do Instituto de Atendimento e Pesquisa em Equoterapia. A aceitação quase unânime do público pesquisado 
pela forma de comunicação online demonstra quantas melhorias poderiam ser feitas dentro da empresa, os temas de maior interesse e onde a empresa pode investir inclusive como propaganda institucional. Saber ligar o lado humanitário e empresarial, neste caso, pode ser considerada a fórmula de sucesso da organização para dar um passo a mais em seu crescimento. No futuro é possível que organizações pequenas como o caso do IAPE se habilitem a investir em pequenas ações como esta, este trabalho abre apenas uma das portas para que futuramente outras empresas valorizem cada vez mais a comunicação interna.

Este estudo buscou ser uma ponte para futuros trabalhos que abordem a comunicação online em empresas e que ajudem as mesmas em seu desenvolvimento. Muitos pontos ainda estão por ser abordados em futuros estudos visto que a comunicação online é rápida e está em constante mudança, porém se deixa aqui uma semente para um segmento rico teoricamente e igualmente na sua prática.

(Recebido em 10/09/2013, aprovado em 10/12/2013)

\section{Referências}

BESERRA DE FARIAS, Luiz Alberto. Poder e Cultura nas Organizações Contemporâneas. São Paulo, s.d. Disponível em: <http://pt.scribd.com/doc/54869105/PODER-E-CULTURANAS-ORGANIZACOES-CONTEMPORANEAS> Acessado em: 30 jan.2012.

CASTELLS, Manuel. A sociedade em rede: Economia, sociedade e cultura. 9. ed. atualizada. Vol. 1. São Paulo: Paz e Terra, 2006.

INSTITUTO DE ATENDIMENTO E PESQUISA EM EQUOTERAPIA. Instituto De Atendimento E Pesquisa Em Equoterapia E Responsabilidade Social. Curitiba, 2009. Disponível em: <http://www.hipicaparanaense.com.br/equoterapia.asp> Acessado em: 30 jan. 2012.

LEITÃO, Leopoldo Gonçalves. Relações terapêuticas: Um Estudo exploratório sobre Equitação Pisco-Educacional (EPE) e autismo. Lisboa, 2004, p. 335-336.

MEDEIROS, Mylena e DIAS, Emília. Equoterapia, Bases e fundamentos. Rio de Janeiro: Ed. Revinter, 2002, p.34.

SANTAELLA, Lucia. Comunicação e Pesquisa. São Paulo: Hacjer Editores, 2001, p.143.

SERRA, Paulo. Internet e Interatividade. Portugal: Universidade da Beira Interior, 2006, p.7. Disponível em: <http://chile.unisinos.br/pag/serra-paulo-internet-interactividade.pdf> Acessado em 30 jan.2012.

SROUR, Robert. Poder, cultura e ética nas organizações. São Paulo: Editora Campus, 1998. 